OPEN ACCESS

Edited by:

Dimitrios Vassilopoulos,

National and Kapodistrian University

of Athens School of Medicine,

Greece

Reviewed by:

Cristina Pamfil,

Iuliu Hatieganu University Cluj,

Romania

Theodoros Dimitroulas,

Aristotle University of Thessaloniki,

Greece

*Correspondence:

Maria J. Gonçalves

mjoaomgoncalves@gmail.com

Specialty section:

This article was submitted to Rheumatology,

a section of the journal

Frontiers in Medicine

Received: 27 December 2016 Accepted: 06 February 2017

Published: 01 March 2017

Citation:

Gonçalves MJ, Mourão AF, Martinho A, Simões O,

Melo-Gomes J, Salgado M,

Estanqueiro P, Ribeiro C, Brito I,

Fonseca JE and Canhão H (2017) Genetic Screening of Mutations

Associated with Fabry Disease in a Nationwide Cohort of Juvenile

Idiopathic Arthritis Patients.

Front. Med. 4:12.

doi: 10.3389/fmed.2017.00012

\section{Genetic Screening of Mutations Associated with Fabry Disease in a Nationwide Cohort of Juvenile Idiopathic Arthritis Patients}

\author{
Maria J. Gonçalves ${ }^{1,2 *}$, Ana F. Mourão 2,3 , António Martinho4, Olívia Simões 4 , \\ José Melo-Gomes ${ }^{5}$, Manuel Salgado ${ }^{6}$, Paula Estanqueiro ${ }^{6}$, Célia Ribeiro ${ }^{7}$, \\ Iva Brito ${ }^{8}$, João E. Fonseca ${ }^{1,2}$ and Helena Canhão ${ }^{9}$
}

${ }^{1}$ Rheumatology Department, Hospital Santa Maria, Lisbon Academic Medical Centre, Lisboa, Portugal, ${ }^{2}$ Rheumatology Research Unit, Instituto de Medicina Molecular, Faculdade de Medicina da Universidade de Lisboa, Lisboa, Portugal, ${ }^{3}$ Rheumatology Department, Centro Hospitalar de Lisboa Ocidental, Lisboa, Portugal, ${ }^{4}$ Centro de Histocompatibilidade do Centro, Coimbra, Portugal, ${ }^{5}$ Instituto Português de Reumatologia, Lisboa, Portugal, ${ }^{6}$ Pediatric Rheumatology Unit, Hospital Pediátrico de Coimbra, Coimbra, Portugal, ${ }^{7}$ Rheumatology Department, Hospital de Faro, Faro, Portugal, ${ }^{8}$ Rheumatology Department, Centro Hospitalar S. João, Porto, Portugal, ${ }^{9}$ EpiDoC, CEDOC, Nova Medical School, Lisbon, Portugal

Fabry's disease (FD) is a lysosomal storage disorder associated with an alpha-galactosidase A deficiency. The prevalence of FD among juvenile idiopathic arthritis (JIA) patients with established diagnosis is unknown, but as musculoskeletal pain may be an important complaint at presentation, misdiagnosed cases are anticipated. With this study, we aim to calculate the frequency of FD-associated mutations in a cohort of JIA patients. Children with JIA from a national cohort were selected. Clinical and laboratorial information was recorded in the Portuguese rheumatic diseases register (http://Reuma.pt). Molecular genetic testing to detect GLA gene mutations was performed. After the multiplex polymerase chain reactions technique for DNA amplification, direct sequencing of the complete sequence of GLA gene was completed. From a cohort of 292 patients with JIA (188 females, 104 males), mutations were identified in 5 patients (all female). Four patients had the mutation D313Y, a rare GLA variant, which is associated with low enzymatic levels in plasma, but normal lysosomal levels. One patient presented the missense mutation R118C, which was previously described in Mediterranean patients with FD. This is the first screening of FD mutations in a cohort of JIA patients. No "classic" pathogenic FD mutations were reported. The late-onset FD-associated mutation, R118C, was found in a frequency of 0.34\% (1/292).

Keywords: Fabry disease, pain, juvenile idiopathic arthritis, cohort, register

\section{INTRODUCTION}

Fabry's disease (FD) is a lysosomal storage disorder initiated by sphingolipid accumulation within lysosomes owing to an alpha-galactosidase A (alpha-Gal A) deficiency $(1,2)$. It is a monogenetic defect inherited in an X-related recessive manner (3). The defects in the GLA gene are heterogeneous, with over 649 mutations recorded according to The Human Gene Mutation Database (accessed 27th October 2015); the majority of these mutations are missense or nonsense (4). This enzyme defect generates progressive accumulation of globotriaosylceramide $\left(\mathrm{Gb}_{3}\right)$ and related glycosphingolipids, primarily in the vascular endothelium (5). 
Reported FD incidences range from 1 in 476,000 to 1 in 117,000 in the general population, and its estimated prevalence among males is around $1 / 40,000(5,6)$.

Classically, affected hemizygous males present with joint pain (60-80\% of the patients), cutaneous lesions (angiokeratomas), and gastrointestinal (GI) symptoms (abdominal pain, diarrhea, and vomiting) $(5,7)$. Autonomic nerve system damage can appear early in the disease course, with patients reporting absence or decrease of sweating. Notwithstanding the absence of major organ dysfunction, these early symptoms, including arthralgia, can produce significant morbidity, limiting the quality of life of affected children (7).

During the course of the disease, more severe manifestations occur, including renal, cardiac, and cerebrovascular complications.

Contradicting a previous belief that women who are heterozygotic for disease causing mutations have a mild phenotype, an analysis from the Fabry Outcome Survey revealed that the majority of these females report clinical features of Fabry disease (8). Indeed, severe manifestations of disease were present, with $77 \%$ of women reporting neurological involvement, 59\% cardiac involvement, and $40 \%$ renal involvement, although the onset of symptoms was not as early as is typically observed in males (9). A considerable delay between onset of symptoms and diagnosis in this group of women was also observed, underlining the importance of careful and longitudinal assessment of female heterozygote patients with FD (9). Recently, definite FD diagnostic criteria were defined, both for male and female patients (see Table S1 in Supplementary Material) (10).

Fabry's disease is rare but causes high comorbidity and increases mortality. However, if early diagnosed can be treatable. Enzyme replacement therapy (ERT) with agalsidase beta has positive results, decreasing neuropathic pain (11) and reducing major organ complications (such as left ventricle hypertrophy) (12).

The screening of high-risk populations seems to be the best cost-effective strategy to diagnose new cases and intervene earlier. As musculoskeletal pain may be a chief complaint, children with joint pain may be considered a population at risk. Two types of pain in FD patients have been described: (1) episodes of burning pain in the extremities, radiating inwards, associated with low-grade fever; (2) acroparesthesias (chronic neuropathic pain in the extremities) $(13,14)$. These episodes tend to express early in the disease course (first and second decades of life) (8).

Juvenile idiopathic arthritis (JIA) is the commonest cause of chronic arthritis in childhood-0.07-4.01 per 1,000 children worldwide is affected (15). In the oligoarticular subtype (50-80\% of all children with JIA), lower extremities are predominantly affected, with the knee being the most frequently involved joint, followed by the ankle (16). Also, in children and teenagers with enthesitis-related JIA, lower extremity pain is common (17). Furthermore, pain scores in Fabry disease were similar to those observed in a group of children with JIA (7).

The prevalence of FD among patients diagnosed as JIA is unknown. The correct diagnosis can prevent the progression of FD and avoid unjustifiable immunosuppression.

\section{MATERIALS AND METHODS}

We aimed to calculate the frequency of FD in a population of JIA patients by GLA genotyping. Carriers of Fabry's-associated mutations were further characterized.

Children and young adults (mean age 17.7 years and 11 years of mean disease duration) from a JIA cohort of patients consecutively included from Paediatric Rheumatology centres in Portugal Mainland and Islands. All patients were diagnosed by an expert physician in the field and classified according to the International League of Associations for Rheumatology (ILAR) criteria (18). Clinical and laboratorial information was recorded at regular time points, according to clinical practice, in the Portuguese nationwide register http://Reuma.pt.

Additionally, a questionnaire with clinical information and a laboratorial evaluation of relevant data in the context of JIA were also performed in these patients. Blood samples collected have been stored at the IMM Biobank, Lisbon Academic Medical Centre.

This study was submitted to the Local Ethics Committee, at Hospital de Santa Maria, Lisbon Academic Medical Centre. For being included in the study, parents and patients gave their informed written consent.

Molecular genetic testing to identify GLA mutations was performed in the Centre of Histocompatibility in Coimbra. Direct sequencing was performed for samples from all patients in order to identify the precise mutation. Multiplex polymerase chain reactions with primers located in intron-exon boundaries were performed in order to allow sequencing of the complete coding region of GLA gene (seven exons). The GLA gene sequencing was performed in 3130 ABI sequencing platform (Applied Biosystems), and data were analyzed with SeqScape v3.0 and Geneious R9 software. Direct sequencing of the appropriate amplified fragment was a feasible strategy due to the development of rapid and sensitive automated sequencers. Control samples from healthy individuals were run in parallel with patients' samples in order to confirm the consensus sequence for all the amplified exons.

\section{RESULTS}

Two hundred ninety-two patients (188 females, 104 males) from our JIA cohort were enrolled, including patients from Portugal Mainland and Azores and Madeira islands (Table 1). A female predominance was present $(64.3 \%)$, and the mean current age and disease duration were $17.7 \pm 9.2$ and $11.0 \pm 8.3$ years, respectively. The most frequent forms of JIA (ILAR Classification) were oligoarticular (persistent and extended), comprising almost half of the patients, followed by polyarticular seronegative form (16.8\%).

Mutations were identified in five unrelated patients (all females)-Table 2. Four patients had the alpha-Gal A gene mutation D313Y (GAT to TAT at cDNA nucleotide 937), and one patient presented the mutation R118C (a missense mutation)-electropherogram (Figure 1). The mutations were found in patients from five centers in four different cities (Oporto, Coimbra, Lisbon, and Faro), showing a non-clustered distribution of the alterations D313Y and R118C. 
The patient with the $\mathrm{R} 118 \mathrm{C}$ mutation is a 9-year-old girl who was diagnosed with oligoarticular JIA and uveitis when she was 3 years old. Joint involvement was restricted to knee episodes of arthritis, managed initially with intra-articular steroid injections and since 2010 with subcutaneous methotrexate. She never had skin lesions and GI symptoms, and her electrocardiogram was normal. Her labs were unremarkable, except for positive antinuclear antibodies at a titer of $1 / 160$ and increased inflammatory markers. She had normal levels of plasma globotriaosylsphingosine (lyso-Gb3) $(1.2 \mathrm{ng} / \mathrm{mL}, N<1.8 \mathrm{ng} / \mathrm{mL})$. Her family history is unremarkable for stroke at young age ( $<55$ years), end-stage renal disease or premature death (before the fifth decade of life). Her mother suffers from Wolff-Parkinson-White (WPW) syndrome, and her father is type 2 diabetic non-insulin treated. One of her two sisters was born with hip dysplasia but with that exception her three siblings (aged 15, 16, and 18) are healthy.

The clinical history from the four patients with D313Y mutation was also revised. Patients were unremarkable for pain with neuropathic features, skin lesions, and GI symptoms. None of the JIA patients suffered from stroke, myocardiopathy, or chronic kidney disease. Their family members did not show any relevant finding, including chronic kidney disease, cardiac anomalies, and cerebrovascular events at young age.

TABLE 1 | Clinical features of the JIA cohort.

\begin{tabular}{lr}
\hline Cohort of JIA patients $(\boldsymbol{n}=\mathbf{2 9 2})$ & (\%) \\
\hline Female gender & 64.3 \\
Age [mean (SD)] & $17.7(9.2)$ \\
Age at diagnosis [mean (SD)] & $8.0(5.0)$ \\
Disease duration [mean (SD)] & $11.0(8.3)$ \\
JIA International League of Associations & \\
for Rheumatology classification & \\
Persistent oligoarticular & 33.0 \\
Extended oligoarticular & 15.8 \\
Polyarticular RF- & 16.8 \\
Polyarticular RF+ & 8.9 \\
Psoriatic arthritis & 5.5 \\
Enthesitis-related JIA & 12.0 \\
Systemic JIA & 7.9 \\
Other features & \\
Uveitis & 13.7 \\
Patients treated with cDMARDs & 79.5 \\
Patients treated with biologic DMARDs & 20.2
\end{tabular}

CDMARDs, conventional drug modifying anti-rheumatic disease drugs; JIA, juvenile idiopathic arthritis; $R F$, rheumatoid factor.

\section{DISCUSSION}

To our knowledge, this was the first study in which FD was screened in a large cohort of JIA patients. No "classic" pathogenic FD mutations were found. The late-onset FD-associated mutation (R118C) was reported in a frequency of $0.34 \%$ ( 1 in 292 individuals) within this nationwide JIA cohort.

Several screenings of FD have been pursued in young adults with stroke, including one in a Portuguese population (19), in hemodialyzed patients (20) and in patients with hypertrophic cardiomyopathy (21). Our cohort is the youngest to be screened until the present moment, as far as we know. Screening of young populations for FD may become particularly important as some advocate initiation of ERT in children (22), although the international position paper (2015) adopt a more cautious view (23).

The mutational analysis through direct sequencing performed to screen for FD assured the same sensitivity for both genders, overcoming the limitations of alpha-Gal activity assays to diagnose FD in females.

The most commonly mutation found in our population was D313Y, which pathological significance for FD has been doubted, because in general D313Y patients do not present clinical manifestations typical of FD (24). Also, it was also proven that Gb3 does not accumulate in the lysosomes of D313Y patients (24).

R118C mutation was reported for the first time in a screening of 37,104 consecutive newborn males in Italy (25). R118C mutation was found in a neonate deficient in alpha-Gal A activity (double assay). This missense mutation had structural characteristics and in vitro overexpression levels similar to those of known later-onset missense mutations (25).

As our patient is a female and $\mathrm{R} 188 \mathrm{C}$ is a mutation associated to late-onset FD, we cannot ascertain a final diagnosis of FD.

The patient and her family are under further clinical investigation. According to diagnostic criteria (15), there is no need to access enzymatic activity (as it can be normal in a female patient). It should be verified if classical symptoms develop or if her parents have definite FD diagnosis carrying the same GLA mutation.

The patient's mother suffers from WPW syndrome, and an association of WPW with autosomal dominant familial hypertrophic cardiomyopathy has been described (26). However, there are no reports of a direct association of FD and WPW.

A low threshold for FD in JIA patients should be warranted, as pain maybe an initial manifestation during the first decades of life $(7,8)$. Also, a family history of strokes at young age, early onset chronic kidney disease, or myocardiopathy should further elevate the clinical suspicion.

TABLE 2 | Clinical and demographic features of the patients with mutations.

\begin{tabular}{|c|c|c|c|c|c|c|}
\hline Patient & Mutation & Form of juvenile idiopathic arthritis & Associated conditions & $\begin{array}{l}\text { Current age } \\
\text { (years) }\end{array}$ & Age at disease onset (years) & Treatment \\
\hline 1 & $\mathrm{R} 118 \mathrm{C}$ & Persistent oligoarticular & Uveitis & 6 & 3 & MTX, NSAID \\
\hline 3 & D313Y & Polyarticular RF- & Cervical Spine Involvement & 19 & 4 & ETA, MTX, NSAID \\
\hline 4 & D313Y & Persistent oligoarticular & - & 25 & 9 & MTX, NSAID \\
\hline 5 & D313Y & Persistent oligoarticular & Uveitis & 9 & 8 & MTX, NSAID \\
\hline
\end{tabular}

ETA, etanercept; MTX, methotrexate; NSAID, non-steroid anti-inflammatory drugs; RF, rheumatoid factor. 


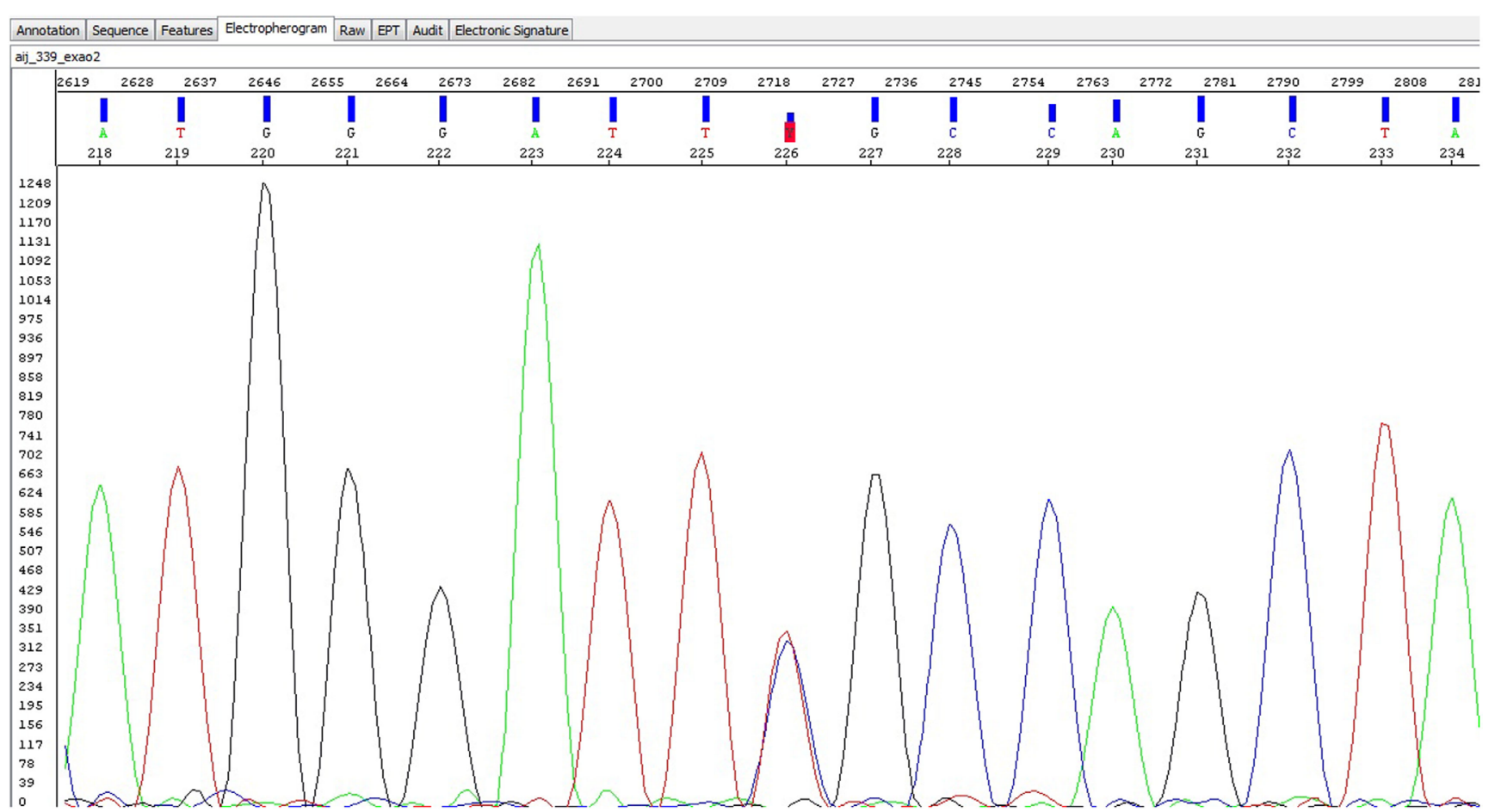

FIGURE 1 | Electropherogram of the R118C mutation

Late manifestations of FD, namely, poststroke status, endstage renal disease, and hypertrophic myocardiopathy, are associated with high morbidity and mortality. On the contrary, early diagnosis of FD can lead to implementation of a specific therapy and allow for the study of their families and respective early treatment if justified. Therefore, finding strategies to screen younger populations, in whom such events could be prevented, seems crucial.

Cost-effectiveness of population screening, even in high-risk groups is difficult to estimate, considering the high direct and indirect costs of this disease in late stages, but also the high cost of enzyme replacement therapies.

Further studies should assess optimal ways of defining highrisk young populations, maybe by combining family history with the presence of symptoms, such as those occurring in JIA.

\section{AUTHOR CONTRIBUTIONS}

MG and AFM wrote the main manuscript text; $\mathrm{AM}$ and OS did the laboratory work; MG, AFM, JM-G, MS, PE, CR, and IB collected

\section{REFERENCES}

1. Brady RO, Gal AE, Bradley RM, Martensson E, Warshaw AL, Laster L, et al. Enzymatic defect in Fabry's disease. Ceramidetrihexosidase deficiency. N Engl J Med (1967) 276:1163-7. doi:10.1056/NEJM196705252762101

2. Bernstein HS, Bishop DF, Astrin KH, Kornreich R, Eng CM, Sakuraba H, et al. Fabry disease: six gene rearrangements and an exonic point mutation in the alpha-galactosidase gene. J Clin Invest (1989) 83:1390-9. doi:10.1172/ JCI114027 clinical data; JF and HC designed the research project. All authors reviewed the manuscript and approved the final version.

\section{ACKNOWLEDGMENTS}

The authors thank all clinicians who collaborated in http:// Reuma.pt and Fernando Martins, IT staff. The authors also thank Dr. Patrício Aguiar's input, from the metabolic diseases clinic, Hospital de Santa Maria.

\section{FUNDING}

This study was sponsored by an unrestricted grant from Shire-Portugal.

\section{SUPPLEMENTARY MATERIAL}

The Supplementary Material for this article can be found online at http://journal.frontiersin.org/article/10.3389/fmed. 2017.00012/full\#supplementary-material.

3. Eng CM, Resnick-Silverman LA, Niehaus DJ, Astrin KH, Desnick RJ. Nature and frequency of mutations in the alpha-galactosidase a gene that cause Fabry disease. Am J Hum Genet (1993) 53:1186-97.

4. The Human Gene Mutation Database at the Institute of Medical Genetics in Cardiff (2016). Available from: http://www.hgmd.cf.ac.uk/

5. Germain DP. Fabry disease. Orphanet JRare Dis (2010) 5:30. doi:10.1186/ 1750-1172-5-30

6. Meikle PJ, Hopwood JJ, Clague AE, Carey WF. Prevalence of lysosomal storage disorders. JAMA (1999) 281:249-54. 
7. Ries M, Gupta S, Moore DF, Sachdev V, Quirk JM, Murray GJ, et al. Pediatric Fabry disease. Pediatrics (2005) 115:e344-55. doi:10.1542/peds.2004-1678

8. Mehta A, Ricci R, Widmer U, Dehout F, Garcia de Lorenzo A, Kampmann C, et al. Fabry disease defined: baseline clinical manifestations of 366 patients in the Fabry Outcome Survey. Eur J Clin Invest (2004) 34:236-42. doi:10.1111/j.1365-2362.2004.01309.x

9. Deegan PB, Baehner AF, Barba Romero MA, Hughes DA, Kampmann C, Beck $\mathrm{M}$, et al. Natural history of Fabry disease in females in the Fabry Outcome Survey. J Med Genet (2006) 43:347-52. doi:10.1136/jmg.2005.036327

10. Smid BE, van der Tol L, Cecchi F, Elliott PM, Hughes DA, Linthorst GE, et al. Uncertain diagnosis of Fabry disease: consensus recommendation on diagnosis in adults with left ventricular hypertrophy and genetic variants of unknown significance. Int J Cardiol (2014) 177:400-8. doi:10.1016/j. ijcard.2014.09.001

11. Hilz MJ, Brys M, Marthol H, Stemper B, Dütsch M. Enzyme replacement therapy improves function of C-, Adelta-, and Abeta-nerve fibers in Fabry neuropathy. Neurology (2004) 62:1066-72.

12. Rombach SM, Smid BE, Linthorst GE, Dijkgraaf MG, Hollak CE. Natural course of Fabry disease and the effectiveness of enzyme replacement therapy: a systematic review and meta-analysis: effectiveness of ERT in different disease stages. J Inherit Metab Dis (2014) 37:341-52. doi:10.1007/s10545-014-9677-8

13. Aldenhoven M, Sakkers RJ, Boelens J, de Koning TJ, Wulffraat NM. Musculoskeletal manifestations of lysosomal storage disorders. Ann Rheum Dis (2009) 68:1659-65. doi:10.1136/ard.2008.095315

14. Pagnini I, Borsini W, Cecchi F, Sgalambro A, Olivotto I, Frullini A, et al. Distal extremity pain as a presenting feature of Fabry's disease. Arthritis Care Res (Hoboken) (2011) 63:390-5. doi:10.1002/acr.20385

15. Prince FH, Otten MH, van Suijlekom-Smit LW. Diagnosis and management of juvenile idiopathic arthritis. BMJ (2010) 341:c6434. doi:10.1136/bmj.c6434

16. Giancane G, Consolaro A, Lanni S, Davì S, Schiappapietra B, Ravelli A. Juvenile idiopathic arthritis: diagnosis and treatment. Rheumatol Ther (2016) 3(2):187-207. doi:10.1007/s40744-016-0040-4

17. Weiss PF, Klink AJ, Behrens EM, Sherry DD, Finkel TH, Feudtner C, et al. Enthesitis in an inception cohort of enthesitis-related arthritis. Arthritis Care Res (Hoboken) (2011) 63(9):1307-12. doi:10.1002/acr.20508

18. Petty RE, Southwood TR, Manners P, Baum J, Glass DN, Goldenberg J, et al. International League of Associations for Rheumatology classification of juvenile idiopathic arthritis: second revision, Edmonton, 2001. J Rheumatol (2004) 31:390-2.
19. Baptista MV, Ferreira S, Pinho-E-Melo T, Carvalho M, Cruz VT, Carmona $\mathrm{C}$, et al. Mutations of the GLA gene in young patients with stroke: the PORTYSTROKE study - screening genetic conditions in Portuguese young stroke patients. Stroke(2010)41:431-6.doi:10.1161/STROKEAHA.109.570499

20. Gaspar P, Herrera J, Rodrigues D, Cerezo S, Delgado R, Andrade CF, et al. Frequency of Fabry disease in male and female haemodialysis patients in Spain. BMC Med Genet (2010) 11:19. doi:10.1186/1471-2350-11-19

21. Elliott P, Baker R, Pasquale F, Quarta G, Ebrahim H, Mehta AB, et al. Prevalence of Anderson-Fabry disease in patients with hypertrophic cardiomyopathy: the European Anderson-Fabry Disease Survey. Heart (2011) 97:1957-60. doi:10.1136/heartjnl-2011-300364

22. Borgwardt L, Feldt-Rasmussen U, Rasmussen AK, Ballegaard M, Meldgaard Lund A. Fabry disease in children: agalsidase-beta enzyme replacement therapy. Clin Genet (2013) 83:432-8. doi:10.1111/j.1399-0004.2012.01947.x

23. Biegstraaten M, Arngrímsson R, Barbey F, Boks L, Cecchi F, Deegan PB, et al. Recommendations for initiation and cessation of enzyme replacement therapy in patients with Fabry disease: the European Fabry Working Group consensus document. Orphanet J Rare Dis (2015) 10:36. doi:10.1186/s13023-015-0253-6

24. Niemann M, Rolfs A, Giese A, Mascher H, Breunig F, Ertl G, et al. Lyso-Gb3 indicates that the alpha-galactosidase A mutation D313Y is not clinically relevant for Fabry disease. JIMD Rep (2013) 7:99-102.doi:10.1007/8904_2012_154

25. Spada M, Pagliardini S, Yasuda M, Tukel T, Thiagarajan G, Sakuraba H, et al. High incidence of later-onset Fabry disease revealed by newborn screening. Am J Hum Genet (2006) 79:31-40. doi:10.1086/504601

26. Gollob MH, Green MS, Tang AS, Gollob T, Karibe A, Ali Hassan AS, et al. Identification of a gene responsible for familial Wolff-Parkinson-White syndrome.NEnglJ Med(2001)344:1823-31.doi:10.1056/NEJM200106143442403

Conflict of Interest Statement: The authors declare that the research was conducted in the absence of any commercial or financial relationships that could be construed as a potential conflict of interest.

Copyright (C) 2017 Gonçalves, Mourão, Martinho, Simões, Melo-Gomes, Salgado, Estanqueiro, Ribeiro, Brito, Fonseca and Canhão. This is an open-access article distributed under the terms of the Creative Commons Attribution License (CC BY). The use, distribution or reproduction in other forums is permitted, provided the original author(s) or licensor are credited and that the original publication in this journal is cited, in accordance with accepted academic practice. No use, distribution or reproduction is permitted which does not comply with these terms. 